\title{
Problem Solving, Confidence and Frustration when Carrying out Familiar Tasks on Non-familiar Mobile DeVices
}

\author{
Conrad Attard1'acp10ca@sheffield.ac.uk, \\ Gail Mountain 2, G.A.Mountain@sheffield.ac.uk, \\ Daniela Maria Romano ${ }^{3}$, Daniela.Romano@edgehill.ac.uk \\ 1. Computer Science, University of Sheffield \\ 2. ScHAAR, University of Sheffield \\ 3. Computing, University of Edge hill
}

\begin{abstract}
Smart mobile devices, which are hand-held electronic devices with an advanced operating system (such as the Android platform) connected via a wireless protocol, have become an integral and essential part of our everyday life, and support both social and workplace activities. However, adopting mobile technology within the workplace setting can give rise to challenges that impact user behavior and performance. A study was carried out amongst 90 participants located in two countries, using internet connectivity as a case study. Confidence and frustration have previously been connected with technology competence, but this was not applied to a workplace scenario during problem-solving, when users are assigned an unfamiliar smart mobile device. This research focuses on identifying the link between workplace users' levels of confidence and frustration when seeking to independently solve problems whilst completing familiar tasks on new smart mobile devices. A detailed video analysis of users' attitudes and behavior during problem-solving was conducted, emphasising a correlation between attitudes and behavior towards completing a task.
\end{abstract}

Keywords: usability and problem-solving, self-directed learning, workplace, smart mobile devices, attitude and behavior, technical support. 


\section{Introduction}

Information and communication technologies form an integral aspect of almost all aspects of our life and are required for many work-based tasks. As a result, technology has become an essential tool for employees. As a consequence, the need for IT support has grown.

Over the last decade smart mobile devices (SMDs) have become increasingly available and are shaping new ways of communication and fostering ubiquitous working practices — that is, being able to work from different locations where there is internet connectivity. New technologies - or, indeed, new features within existing technologies - are being released at a fast pace, and if they were to be adopted in the workplace at the same pace they could affect employees' productivity, in addition to users' perceptions of self-confidence. Lazar, Jones, \& Shneiderman (2006) investigated how users felt when they did not have the correct competence to fully and efficiently use technology in the workplace. They found that the lack of competence limited the opportunities for interactions with co-workers through such devices. Therefore, there is an increased need for continuous learning and for providing training support to users in the workplace.

According to Giannakouris \& Smihily (2012), 48\% of enterprises in the EU and nine out of ten large companies provided staff with portable devices that allowed a mobile connection to the internet for business use. Smart mobiles are becoming more accessible in terms of price and availability and more and more users own devices that support pervasive computing technology, although there continues to be a lack of knowledge about users' behaviours and attitudes, especially with regards to their confidence and frustrations when using a new mobile. In addition, further insights are needed with regards to users' behaviour in the workplace, especially when they are faced with problems. More specifically, internet connectivity is one of the main pillars underpinning smart mobile platform usage and is, therefore, one of the first challenges a user encounters when adopting a new device.

The work presented here further investigates attitudes and behaviours when attempting to solve problems independently. A study was carried out focusing on the challenges arising from performing a familiar task on an unfamiliar device. These can occur, for example, when the user acquires a new device at work, either on a permanent or temporary basis, or otherwise needs to learn new ways of using the device due to changes or updates in technology (such as in the case of a new operating system release or a new mobile model). It was assumed that the adoption of mobile technology takes place within, and is supported by, the workplace environment. 
The study attempts to establish how users would overcome the obstacles in their work environment. In particular, it examines how SMDs offer opportunities for self-directed problem solving. We assumed that users would attempt to overcome the obstacles in line with their own level of progression and knowledge base and be able to determine the manner in which they should tackle the various obstacles as well as the challenges they encounter due to their different roles within the organisations, their confidence and attitude, frustration and success rate.

More specifically, the objective of the work presented in this study was to observe and examine the relationship between the length of time it took for the IT helpdesk to provide support and the way in which participants tackled problems in an independent manner. The aim was also to establish if the issues and problems experienced by workplace users differed according to their job roles and skills.

The main concepts considered in relation to the study and technology adoption in the workplace are discussed below.

\section{Usability Issues during Problem-solving when Using SMDs}

Despite the fact that the use of SMDs has increased, and fundamentally changed how people work together, learn and communicate, there is a need to establish a greater awareness of the attitudes and behaviours of users when facing problems in the use of SMD devices. Users must not only learn about the content and procedures, but also how their abilities and soft skills can be developed in such a way to help them to solve problems and to reach their goals.

A report published in 2012 by Eurostat (Giannakouris \& Smihily, 2012) identifies a number of obstacles limiting the usage of portable devices for mobile connection to the internet. For example, approximately $21 \%$ of all EU27 enterprises reported connectivity problems as a barrier; $17 \%$ of them considered technical obstacles or high costs as problematic when integrating internet mobile connections within business applications; and 30\% of all EU27 enterprises identified at least one obstacle, such as problems related to connectivity, cost of proper infrastructure and technical difficulties that limited or prevented their business from using portable devices for internet mobile telephony (Giannakouris \& Smihily, 2012).

The process of problem-solving, in itself, has the advantage that it can contribute to learning. For example, Kleanthous Loizou and Dimitrova (2012) present the findings from a novel computational 
research study of community-tailored support, adopting the objective of helping knowledge-sharing that could be transferred throughout communities. Through a validation study, the research examined the effects of community-adapted notifications and, accordingly, showed that notification messages can improve members' awareness and perceptions of how they relate to others.

Kravcik and Klamma (2012) specifically examined the support of self-regulation through a personal learning environment. Their aim was centered on providing learners with the freedom to design and compile the learning environment in line with their required personal preferences. However, although the study involved students with a high level of education, the feedback collected showed that most of the learners found self-regulation to be challenging. The proposed personal learning environment did not consider how users might tackle problems. Accordingly, more research is needed in an effort to gain a deeper insight into, and a better understanding of attitudes and behaviours when users face difficulties.

Usability is an important aspect of SMDs. Although SMDs have become more useful, in some ways, this comes at the expense of the usability of such devices (Harrison, Flood, \& Duce, 2013). Nielson identifies five attributes of usability, namely, efficiency, satisfaction, learnability, memorability, and errors (Nielsen, 1994)

The proposed experiment investigated various challenges associated with a range of attributes identified in the existing models of usability. In this vein, this paper particularly focuses on the last three of the attributes of usability, whereby users were observed whilst solving problems by considering learnability, memorability, and errors.

Efficiency can be defined as how well a user achieves his/her goal in relation to accuracy and completeness. Satisfaction is the fulfilment of one's expectations or the pleasure derived from using a piece of software. For Neilson (1994), learnability is related to the ease of use of systems and to the rate at which users can achieve the intended outcome. Memorability is an attribute of systems that are easy to remember, where their cognitive load impacts on the usability when configuring or using software. The last attribute investigated by Neilson (1994) and Harrison et al. (2013) is 'errors', which can be identified when performing an evaluation process, capturing how well the user can complete the desired tasks without making mistakes, and further establishing the nature of errors and the frequency with which they occur.

Learning takes place at the learner's initiative when s/he adopts a self-directed learning approach. Such individuals have primary responsibility for planning, implementing, and evaluating the effort 
(Hiemstra,1994). In this study, a learner who can self-direct his/her progress with regards to the learning of IT technology is defined as an independent IT user. Other learners who are initially dependent can progress and become independent, moving from dependency to independency (McAuliffe, Hargreaves, Winter, \& Chadwick, 2008).

Problem-solving is recognised as part of the learning process. For example, Schmidt and Braun (2006) investigated a learning process in a structured way, examining how different individuals in their workplace can make use of the immediacy of purpose and real-world context learning. They argue that optimal solutions should smoothly integrate context-aware learning support systems. Additionally, such systems should consider the awareness aspect of knowing about and taking into account the learning context of the user.

Sense-making, the process that connects data, creates a hypothesis and, accordingly, develops reasoning based on what is being observed when performing a task-based activity, has also been investigated in an effort to achieve a better understanding of the potential offered by learning on SMDs (Rogers, Connelly, Hazlewood, \& Tedesco, 2009). The authors argue that key aspects requiring further research are centered on investigating how users react when facing a problem, their attitudes and behaviour, and their awareness of obstacle-solving strategies. They also argue that in order to efficiently complete a task, the design of an application should help users to recover quickly from errors; as such the use of error messages and system status icons have also been investigated.

Researchers adopt techniques to collect data and evaluate their findings by creating controlled experiments and questionnaires. The latter have been adopted from research methods to evaluate users' attitudes and behaviour and have also been used in usability research (McGuffin \& Balakrisha 2005). Once data is collected using these techniques, the use of statistics in usability research creates the opportunity to deal with numbers, allowing the research to better derive meaningful outcomes (Cairns \& Cox, 2008). The choice of tasks assigned during the experiment and techniques, that will be analysed after the experiment has been completed are a crucial part of any study related to usability ( Dix, 2007; Nielsen \& Landauer, 1993). Session analysis, such as that carried out through the use of video to capture users' actions while completing a given task, requires considerable resources but is an effective method of assessment of the data extracted (for example, data on user actions at various times (Jambon, Golanski, \& Pommier, 2007). When applying this technique a researcher should also consider different methods of assessments such as completing questionnaires prior to and after the task, to enable the researcher to obtain quantitative and qualitative data. (Cairns \& Cox, 2008). 
Organisational structure and workplace practices influence how employees acquire knowledge, which, in turn, is shaped by the different skills needed and the level of competence required to undertake the necessary skills (Ashton, 2004). Problems can arise when there is a lack of knowledge pertaining to what action to take in order to solve a problem (Giannakouris \& Smihily, 2012). Various studies discuss different methods for improving the way in which users interact with mobile devices. For example, Mourão \& Okada (2010) showed that, in this field, there are a number of challenges when using SMD to communicate quickly, accurately, and completely. The authors listed the requirements that need to be considered, including an intuitive user interface where the user interface must provide optimised efficiency due to a high rate of user interaction and the nature of work undertaken.

\section{Confidence, Frustration and Goal-setting in the Workplace}

According to Lazar Jones, \& Shneiderman (2006), when employees face computer problems that need to be solved they become frustrated and, as a result, waste a high percentage of their time, which has an impact on the individuals and their organisations. Time spent trying to solve a problem has been highlighted as a key factor in measuring frustration. Frustration seems to increase when participants spend a larger amount of time trying to solve a problem without achieving satisfactory results. Error messages, connection problems, application freezes, hard-to-find features, and long download times are the top five problems encountered (Lazar, Jones, \& Shneiderman, 2006). Moreover, both confidence and frustration are influenced by the individual's own experience and circumstances surrounding their actions.

Goal-formation and sense of achievement within a short timeframe can be influenced by an individual's self-confidence and their overall ability to use tools such as computer-based devices and software. In the digital age, due to the fast pace at which knowledge is produced, shared, and consumed, there is ever-mounting pressure to ensure that the time between starting and achieving a goal is short. Amongst others, cognition and self-regulation have evolved and are being researched, suggesting the need to clarify the conceptual element of goal setting. Latham \& Locke (2002) infer a strong relationship between goal commitment and performance when the user recognises his/her abilities and the importance of a task. The authors argue that in order to achieve good performance, the goal needs to be specific and individuals must be under no doubt as to what is expected from them. As a result, if a learning goal approach is adopted, this leads to achieving a better performance 
and better results than merely focusing on what is expected from the user (Lunenburg, 2011). An important factor in the process is how a user achieves a particular goal and how this impacts on an individual. Pintrich, Conley, \& Kempler (2003) state that during the last 20 years goals have evolved with different attributes and beliefs pertaining to success, failure, effort, and ability.

\section{Study Rational}

To summarise, mobile technology usage is widespread and its adoption in the workplace presents challenges that could affect user behaviour and performance, as well as confidence and frustration. Usability theories highlight several attributes (learnability, memorability and errors) that a user might need to acquire in order to achieve their goal.

Therefore, there is a need to further investigate smart mobile use within the workplace environment. Being able to understand how a user independently solves these challenges might help to improve the engagement with technology.

The study hypotheses are indicated below:

H1: When given a task on a new SMD in the workplace environment, the majority of the users will experience obstacles. They will attempt to overcome such obstacles in line with their own knowledge base and following their own progression level.

H0: Unfamiliarity with SMDs does not influence task performance. People will not need to attempt to overcome obstacles, and their knowledge base will not be increased. 


\section{$5 \quad$ Materials and Method}

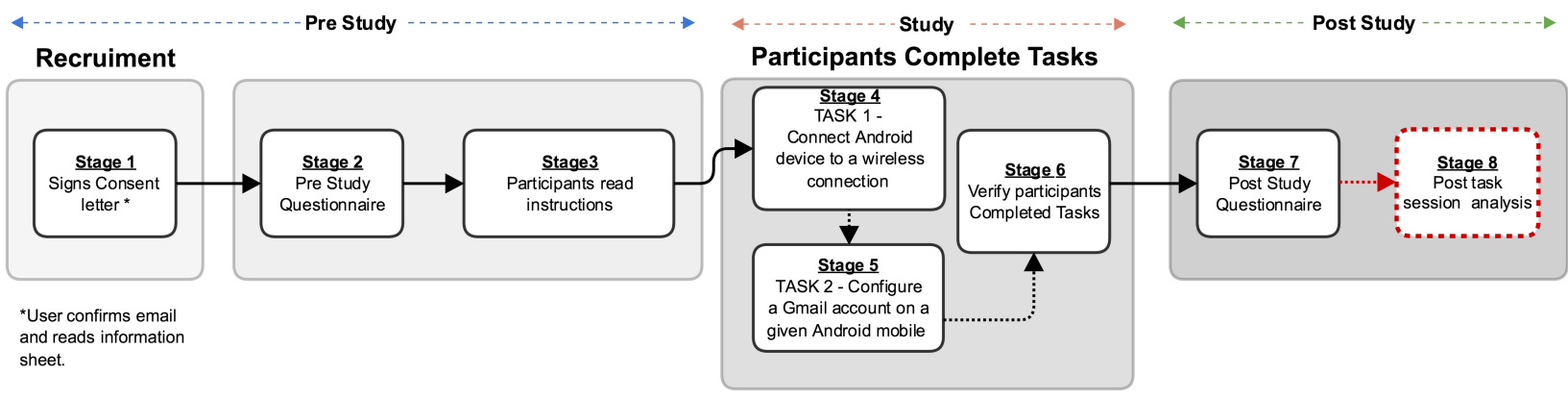

Figure 1: Description of Stages

The data was collected through the administration of pre- and post-session online questionnaires, as described below (section 5.3 and available online ${ }^{1}$ ), as well as through the analysis of video recordings of the participants while completing the two given tasks (See Figure 1). The use of descriptive statistics and diagrams are presented to help understand the data collected at various stages. Using inferential statistics to analyse the data collected, and by comparing different groups under different conditions it was possible to make inferences about the various stages. From stages 4 , 5 and 6, two reviewers annotated the content of the videos as described in section 5.4. They reviewed and analysed the video recordings of the session during which the participants completed the two given tasks. The reviewers logged the data that was evaluated at stage 8 . The following sections describe in the detail the method used for the study.

\subsection{Data Gathering Tools}

Three different SMD platforms were utilised, each with a different operating systems (OS): Android, IOS (Apple), and Windows 7. Moreover, two video cameras were utilised: one to record users' behaviour overall (e.g. frustration during the task), and their time performance (via a camera timer), whilst the other was used to record the users' actions on SMDs.

\footnotetext{
${ }^{1}$ http://www.slideshare.net/conattard/pre-sessionsurvey \& http://www.slideshare.net/conattard/post-sessionsurvey
} 


\subsection{Participants}

Participants were recruited either via email or word of mouth in equal numbers across three locations referred to as collector: the University of Sheffield in the UK, the University of Malta, and the Malta International Airport (MIA). Those who participated volunteered for the study because they had an interest in knowing more about the use of SMDs.

Ninety participants were recruited for the study. The university participants came from different backgrounds, including university lecturers and professors, administration staff and paid researchers. The selection criteria used were that a university user had to receive a salary and have an allocated desk and office for their sole use within their respective university. Participants from MIA included managers, senior administrators and clerical staff.

Amongst the 60 participants recruited from the two universities, 25 per cent (24) were in full-time employment, 5 worked part-time (less than 35 hours per week) and, from amongst the paid researchers, 25 were also studying full-time whilst 6 were studying part-time. Amongst the 30 volunteers recruited from MIA, 22 worked full-time, 4 worked part-time and studied part-time, and 4 worked with reduced hours (less than 35 hours per week). Forty-seven men and forty-three women took part in the study. Participants' ages varied between 16 and 55 years, with a mean average age of 25 years. Participants were given an information sheet (also available online ${ }^{2}$ ) describing the aim of the study and its procedure. A consent form was signed by all participants prior to them taking part, and time was allocated for any questions participants might have before the study began and after the study was completed.

\subsection{Data Collection}

The pre-session questionnaire ${ }^{2}$ was designed with the aim of collecting information relating to demographics (age, gender, computer experience, recent workplace history, and so on), the type of mobile device owned and the habits and way in which participants use their mobile devices. In addition, the questionnaires included a variety of reply modes, such as the value of items utilising a 5-point Likert-type scale, and closed questions (such as Boolean type, categories and multiple-

\footnotetext{
${ }^{2}$ www.conradattard.com/yourspace,
} 
choice) as well as open-ended questions. The researchers formulated the questions. The first sections of the questionnaire aimed at discovering the participants' experiences in relation to their IT support needs. Workplace support was enquired about in general: for example, participants were asked to rate their IT support service performances and the amount of time that elapsed usually between a request for help and the time when IT support became available. Moreover, they were asked to recall a recent problem they had experienced and to describe how it had been handled. With the aim of identifying participants' confidence levels before the session, as well as learning how they felt when they encountered problems with their mobile device, a section of the questionnaire was adapted from that used by, Lazar, Jones, \& Shneiderman (2006) to examine user frustration with technology.

Participants were randomly assigned to a particular OS with which they were unfamiliar. In order to ensure this, before the experiment was carried out each user was asked if s/he was familiar with the OS system to which they had been assigned. If they had already used the OS in question another device with another OS was assigned.

In the last section of the pre-questionnaire participants were asked to complete a test (see Figure 7). A mobile status bar test was assigned in order measure users' competence and ability to recognise SMDs icons. The participants were asked to identify 11 amongst the typical icons found in an SMD status bar (such as connectivity, Bluetooth, etc.). The status bar is normally found at the top of the screen and icons are almost continually displayed when the user is interacting with various apps. The icons indicate the status of the respective service and they also indicate errors and actions that the user may need to be aware of, such as connectivity, battery level, and errors. Icons in common use were chosen for this test.

After completing the pre-questionnaire, participants were given an SMD with default factory configuration, and were asked to complete two tasks in a maximum of 15 minutes: (1) connect to a wi-fi connection and browse a given website; and (2) configure an existing Gmail account on an app, sending an email to a given recipient and checking connectivity. Both tasks required the participant to connect to wi-fi and to verify the connection (see Figure 3 and Figure 4). The second part of each task entailed several steps that could only be completed when wi-fi connectivity had been achieved. The participants were allowed to proceed to the next task only after completing the previous one. 


\subsection{Session Analysis Procedure}

Two reviewers annotated the content of the videos that were used for this study referred to as session analysis (see Figure 2).

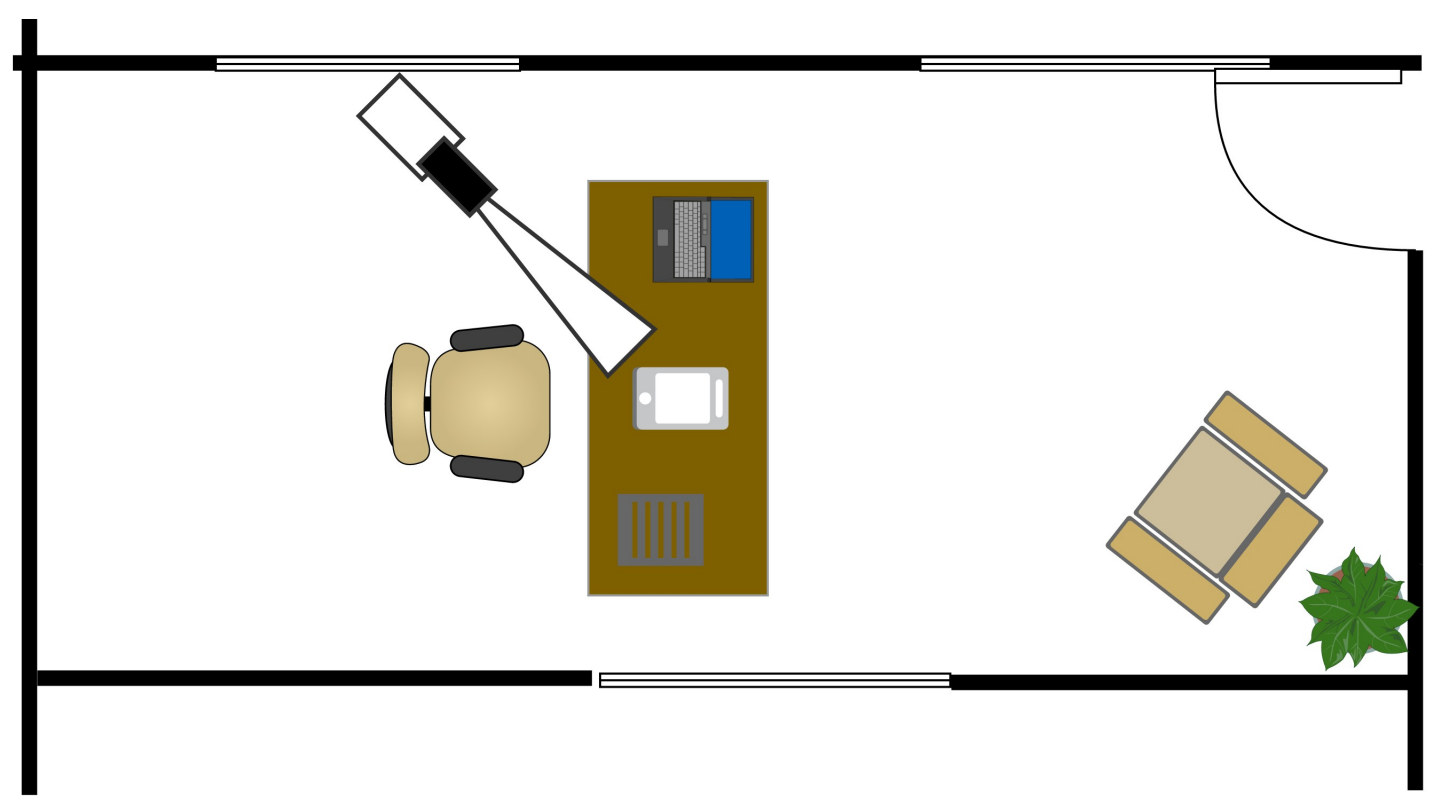

Figure 2 Setup of office where experiment was carried out

It was necessary to review the video for this study three times. The aim of the first review was to identify the iterations and to plan the way in which tasks would be annotated (as listed in Tables 9 and 10). During the second review, each reviewer independently analysed all the videos. The individual assessments were later compared during the third review.

During the first review a list of criteria was established to identify the most important aspects of the behaviour observed in the videos. All aspects identified were collected in an Excel template for later use.

For the first review a sample of nine videos was chosen at random, three from every collector, the University of Sheffield in the UK, the University of Malta, and the Malta International Airport (MIA). For each collector, at least one type of mobile operating system was chosen (HTC Android, HTC Windows Mobile 7.5 and iPhone 4 iOS 6). Each video was selected from those who managed to complete only Task 1 or from those who completed both tasks. If none of the tasks were completed 
by any of the participants a random participant was chosen. This data was available from the prestudy and post-study questionnaire. Each reviewer suggested criteria for inclusion in the final version of the Excel template.

During the second review, the Excel template (created in review one) was used to log the various aspects of users' behaviour as observed independently by the reviewers in all videos. The videos that did not have a view of the mobile screen whilst completing the experiment at critical stages were not included in the analysis. When the screen was obstructed for a long time or where light reflected in such a way that one could not note the choices the user was making at key times, participants were excluded from the analyses. A total of $78 \%(n=70)$ of the videos were considered valid. All information observed was inserted in an Excel template by each of the reviewers, this included a log of the time, the type of approach according to the category, and the iteration completed at that particular stage. Two reviewers carried out the analyses independently at this stage using all the videos.

The third review aimed at the harmonisation of key aspects of the reviewers' independent analyses, such as main obstacles as well as key successful approaches that were completed by participants. If there was any conflict in the independent analyses a discussion took place between the two reviewers. The results presented here are the outcome of the third review.

The third review also helped to address observations that were identified as the review progressed. A total of eight videos $(78 \% ; \mathrm{n}=70)$ identified differences in what was logged by both reviewers. After reviewing the video together it was agreed that they would be excluded from the study. A total of $(69 \% ; n=62)$ were included for further analysis. 
Task 1

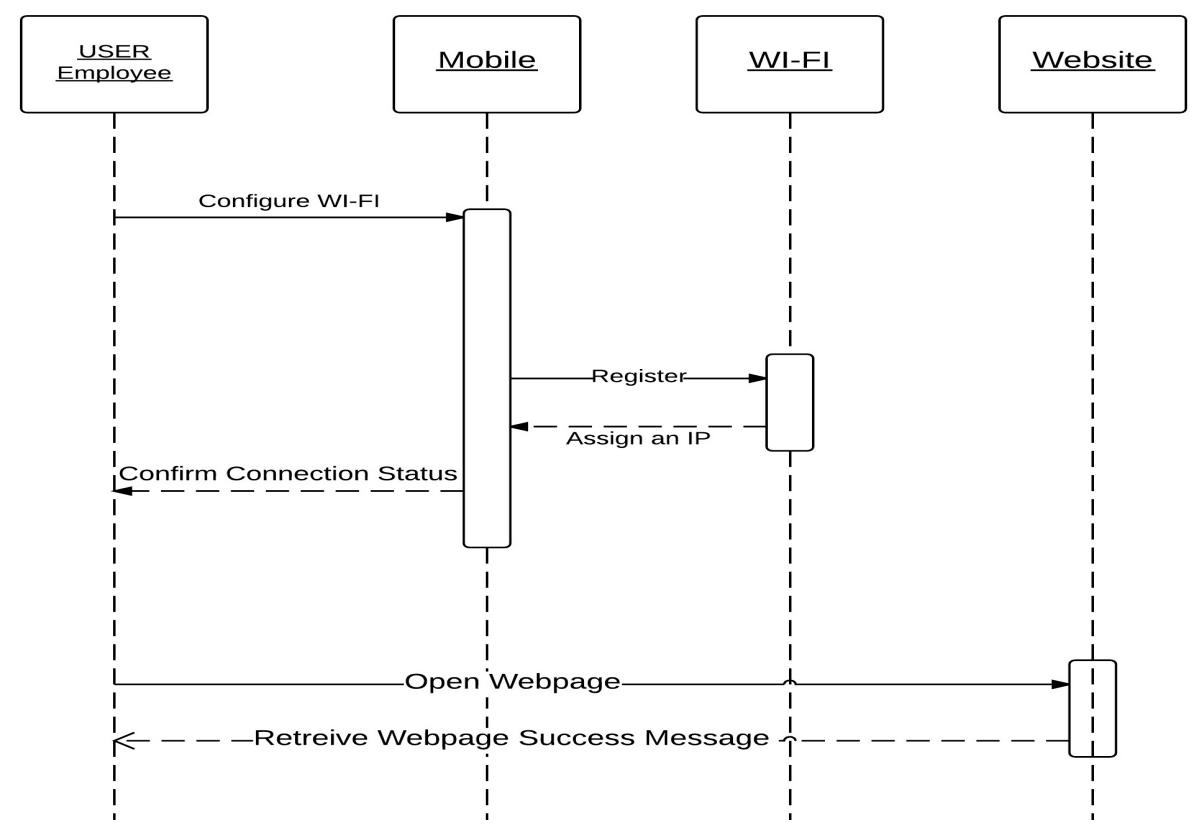

Figure 3: Sequence diagrams of Task 1 
Task 2

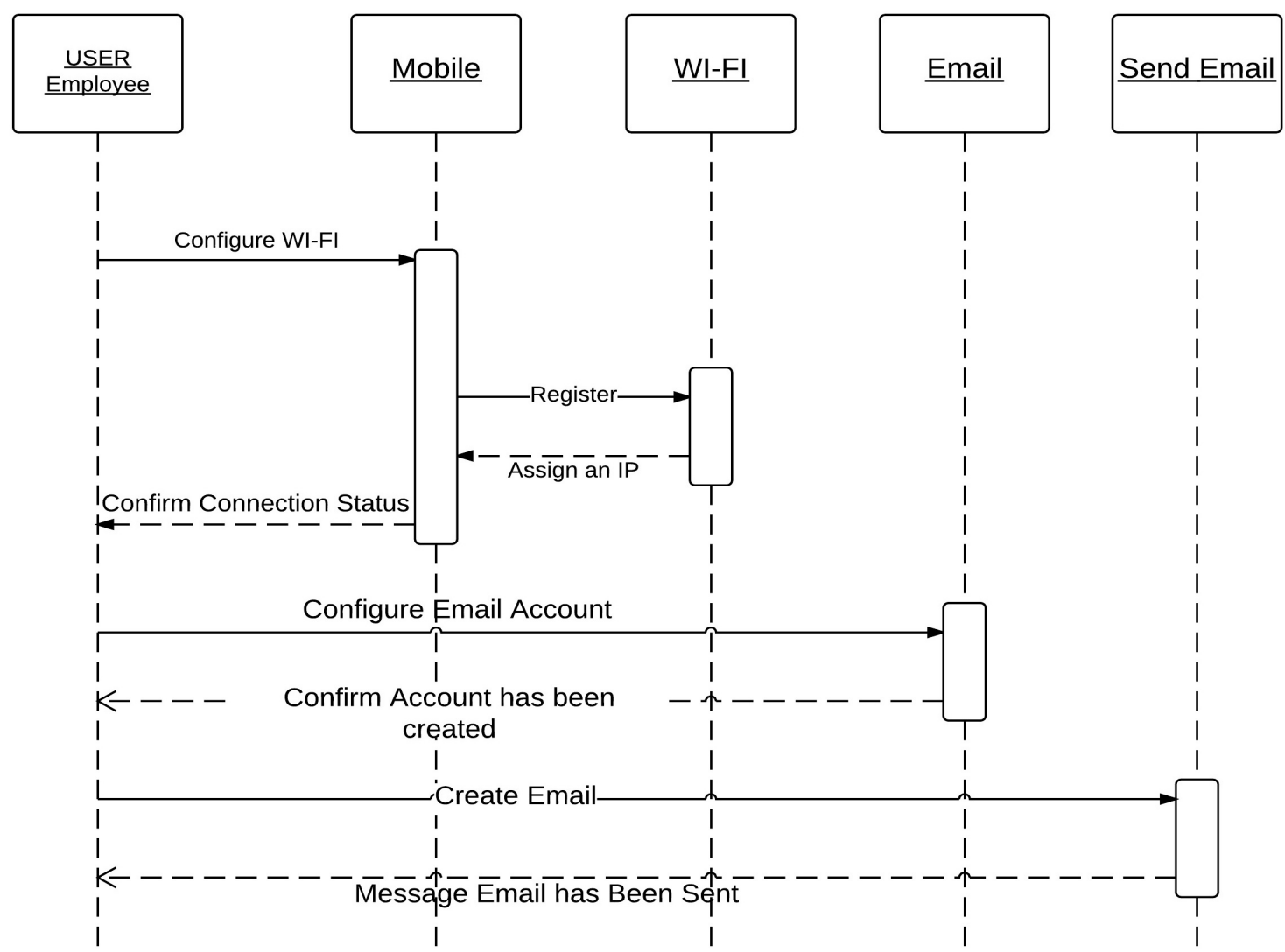

Figure 4: Sequence diagrams of Task 2

The attitude and behaviour of the participants when completing the given tasks was also observed through the use of video recording, as will be explained in section 6.5.

Immediately following the completion of the main task, a post-session questionnaire ${ }^{2}$ (See Figure 1) was distributed to the users with the objective of assessing their experience, particularly with respect to their level of frustration when performing the given task. Each participant was also asked to indicate whether he or she managed to solve Task 1 or Task 2, both, or neither.

\section{Results}

The results obtained from the assigned tasks show that 78 participants $(87 \%, n=90)$ failed to complete Task 2, obtaining a high failure rate in relation to the three main stages: configuring a Gmail account on an app, sending an email, and checking connectivity. For Task 2, 62 of the participants tried various steps and attempted to understand the problems. Of the participants, 23 
$(37 \%, n=62)$ did not attempt to configure the wireless connection and those that attempted did not complete Task 2. Moreover, 18 of them repeated the same action several times without trying different approaches. The performance of three participants was considered invalid, leaving valid participants $n=90$.

The majority of the participants $(78 \%, \mathrm{n}=70)$ managed to complete Task 1 . Some participants $(13 \%$, $\mathrm{n}=12)$ managed to complete both Task 1 and Task 2 . Only a small number of participants $(7 \%, \mathrm{n}=$ 6) failed to complete both tasks (see Table 1).

Table 1: Success in completing the given task

\begin{tabular}{|l|c|c|c|c|c|}
\hline & None & Task 1 only & Task 2 only & Both & Total \\
\hline All participants & 6 & 70 & 2 & 12 & 90 \\
\hline Men & 3 & 35 & 0 & 9 & 47 \\
\hline Women & 3 & 35 & 2 & 3 & 43 \\
\hline
\end{tabular}

A statistical analysis of the data was conducted. A number of tests were applied using the statistical analysis package SPSS (Field, 2009). Moreover, a qualitative analysis of the data collected from the pre- and post-session questionnaires was carried out. The results show that gender was not a differentiating factor between those able to complete the task. These results will be further discussed below in consideration to other factors.

The 'confidence level' and 'perceived frustration' of the participants were measured both before and after the completion of the tasks. The 'confidence' score was generated by averaging the scores of the eight items in Section 8 (questions 1-8) of the pre-session questionnaire, which contained questions related to how the participants were feeling at that particular moment. All these items were rated on a 5-point Likert-type scale ranging from 0 to 4 where 0 corresponds to 'very low confidence' and 4 corresponds to 'very high confidence. The question 'Do you often get upset over things?' had a value 0 for 'strongly disagree' and 4 for 'strongly agree'. As such, the score was inverted and added to the average confidence score. 
The 'perceived frustration' score was generated by averaging the scores of the 6 items (questions 611 ) in the post-session test (and available online ${ }^{3}$ ). All the items were rated on a 5-point Likert scale ranging from $0-4$ ( 2 being the mid-point). Accordingly, the frustration score ranged from $0-4$, where 0 corresponds to 'very low frustration' and 4 corresponds to 'very high frustration'.

Factor analysis was carried out with the aim of discovering the patterns of the relationships between the eight items describing confidence and the six items relating to frustration. The questions concerning confidence are reported below. The questions relating to frustration are reported in the following link: http://tinyurl.com/postsessionsurvey. The dominant factor, Question 7 of the pre-test ('Do you often get upset over things?'), explained $26.97 \%$ of the total variance. This implies that respondents who provided high-rating scores for Question 7 tend to provide lower rating scores for the remaining items, and vice versa. This result conforms to what was expected, whereby obtaining a high score constituting a high level of negativity would trigger low scores - that is, a low level of confidence - in the other questions (see Figure 5).

\footnotetext{
${ }^{3} \mathrm{http}: / /$ www.slideshare.net/conattard/post-sessionsurvey
} 

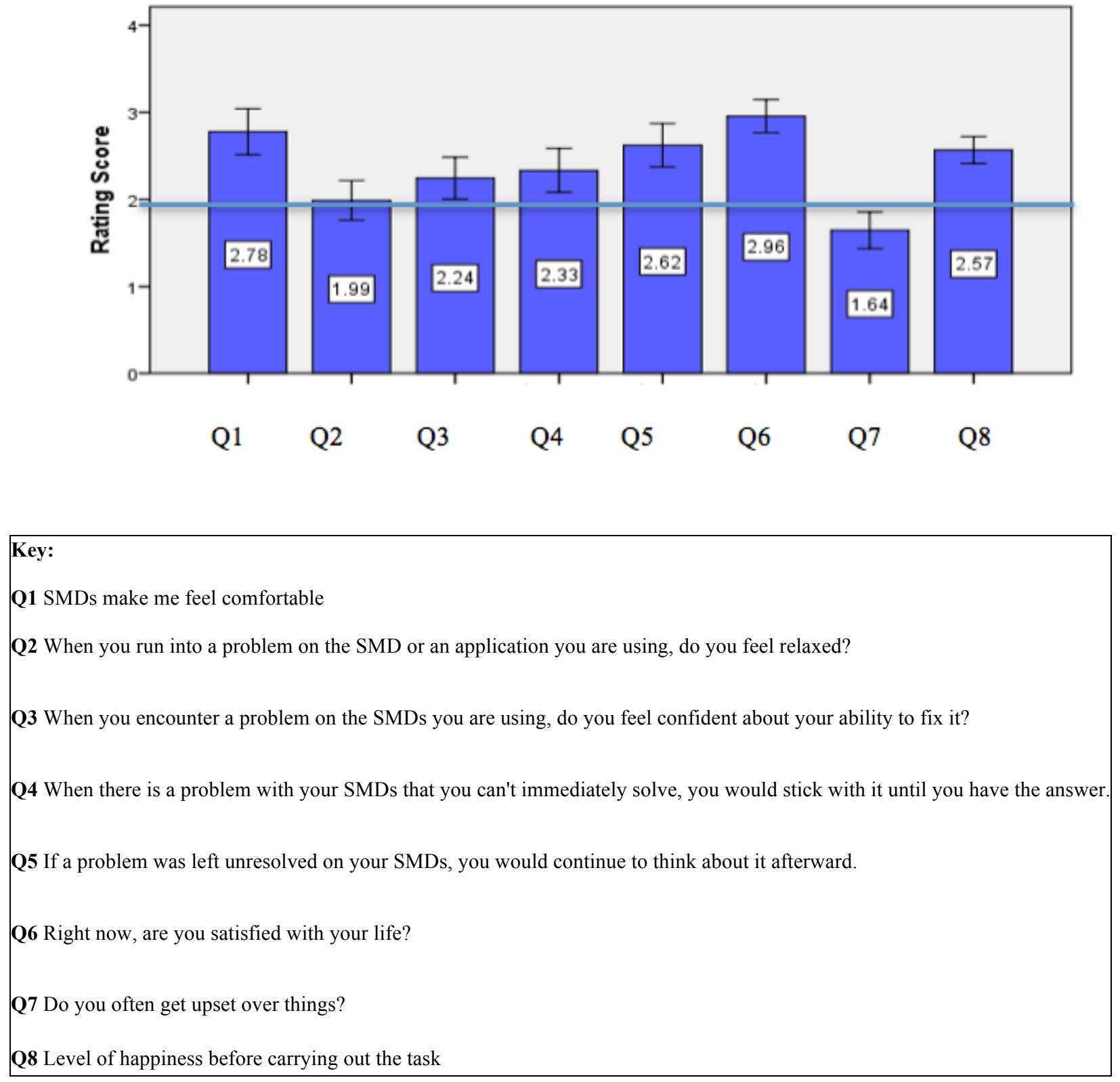

Figure 5: Pre-session 'Confidence' mean score.

With regard to the participants' comfort in using SMDs, a mean score of 2.78 was achieved, indicating that they were quite comfortable with SMD usage. Furthermore, a score of 2.24 was gained in regard to their confidence in fixing any problem; that they would try various routes until a problem was resolved; or that they would continue to think about unresolved problems. On average, the participants were very satisfied with their life, indicating they did not often get upset over things. They also indicated that when they encountered a problem with SMDs, they remained neutral; that is, neither relaxed nor anxious. 
The Kolmogorov-Smirnov test was used to determine whether the distributions of the confidence score and frustration score are normal; this proved to be the case (see Figure 5). The Pearson Correlation was measured and provided a coefficient of -0.225 , indicating a negative relationship between the frustration and confidence scores. This implies that participants who scored highly on 'confidence' had low scores on 'frustration', and vice versa. The Pearson's Correlation Coefficient is used to measure the strength of the relationship between two matric scaled variables with a normal distribution. The Pearson Correlation Coefficient ranged from -1 to 1 , where a large negative value was seen to correspond to a strong negative relationship, and a large positive correlation was seen to correspond to a strong positive relationship.

This negative relationship can be generalised, as it is not attributed to chance since the p-value is 0.033 , which is less than the 0.05 criteria.

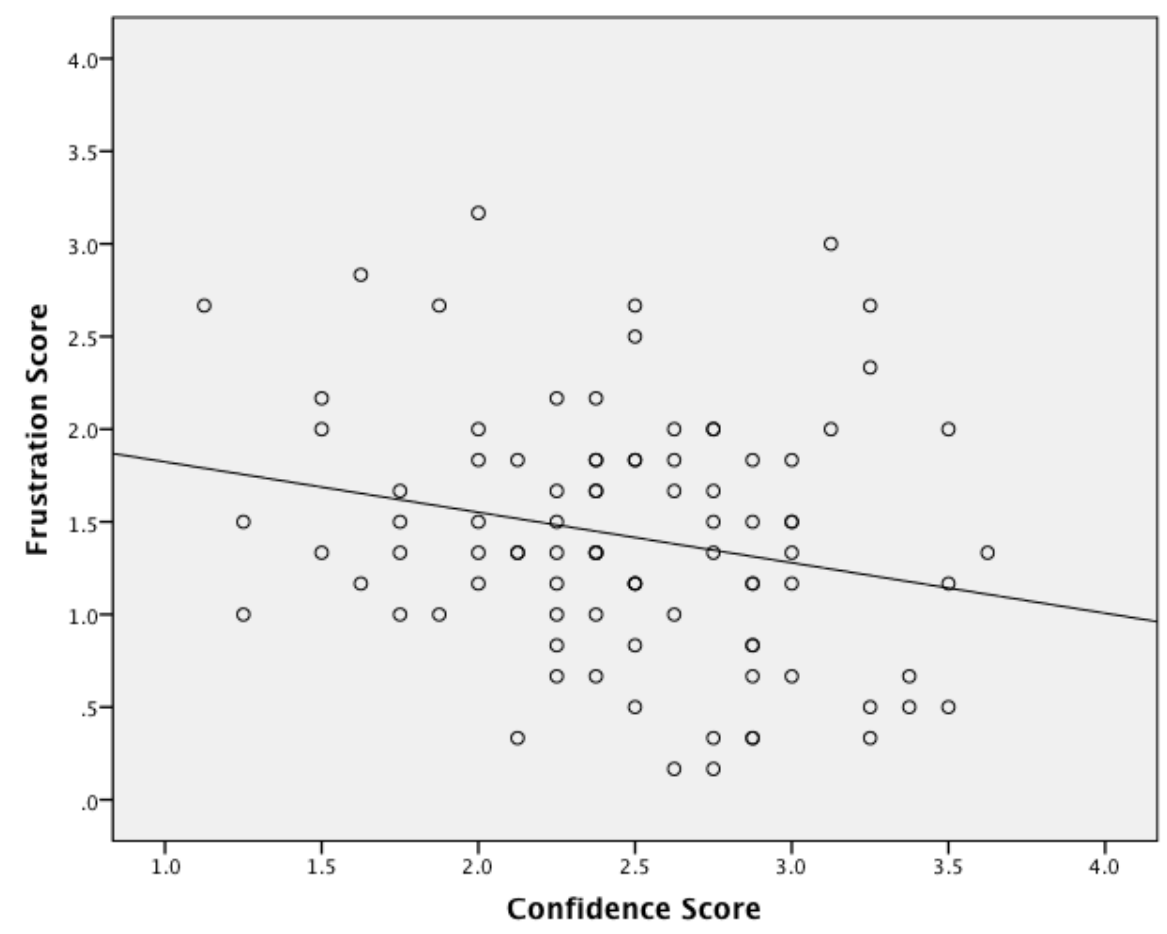

Figure 6. Frustration Score versus Confidence Score

Connectivity to the internet is one of the main challenges identified in this study. Of the sample, 39 participants $(63 \%, n=62)$ who did not manage to solve the problem tried to configure the wi-fi, and 14 participants $(33 \%, n=39)$ identified the problem but did not know how to solve it. It was also observed that 18 participants $(42 \%, n=39)$ seemed to know only one way of completing the task, and they iterated the same sequence of actions a number of times without effectively changing the actions to achieve a solution. The study also considered how users engaged with the mobile. 


\subsection{Job Role, Confidence, and Frustration}

Twenty-five $(28 \%)$ of the participants had a job or were enrolled in studies related to computer science and, therefore, had faced high exposure to technology (see Table 2).

Table 2: Number of participants in different roles

\begin{tabular}{|l|l|l|}
\hline Job Role & Frequency (No) & Percentage \% \\
\hline Manager of a team & 14 & 15.6 \\
Administrator & 17 & 18.9 \\
Clerk & 9 & 10.0 \\
Lecturer & 9 & 10.0 \\
Researcher & 18 & 20.0 \\
IT researcher & 14 & 15.6 \\
IT support & 9 & 10.0 \\
\hline Total & $\mathbf{9 0}$ & $\mathbf{1 0 0 . 0}$ \\
\hline
\end{tabular}

If we consider the relationship between confidence and frustration, and job role, we can observe that the highest average values in confidence are those of university IT researchers, followed by managers, whereas the highest scores of frustration were indicated by managers and university lecturers. The p-values (0.098 and 0.845) for confidence and frustration scores, respectively, exceeded the 0.05 level of significance, thus implying the mean frustration scores did not significantly vary between groups of participants with different roles in the workplace. Confidence was close to 0.05 , implying that the different roles value of confidence varied for each group (see Table 3). 
Table 3. Confidence and Frustration according to job role

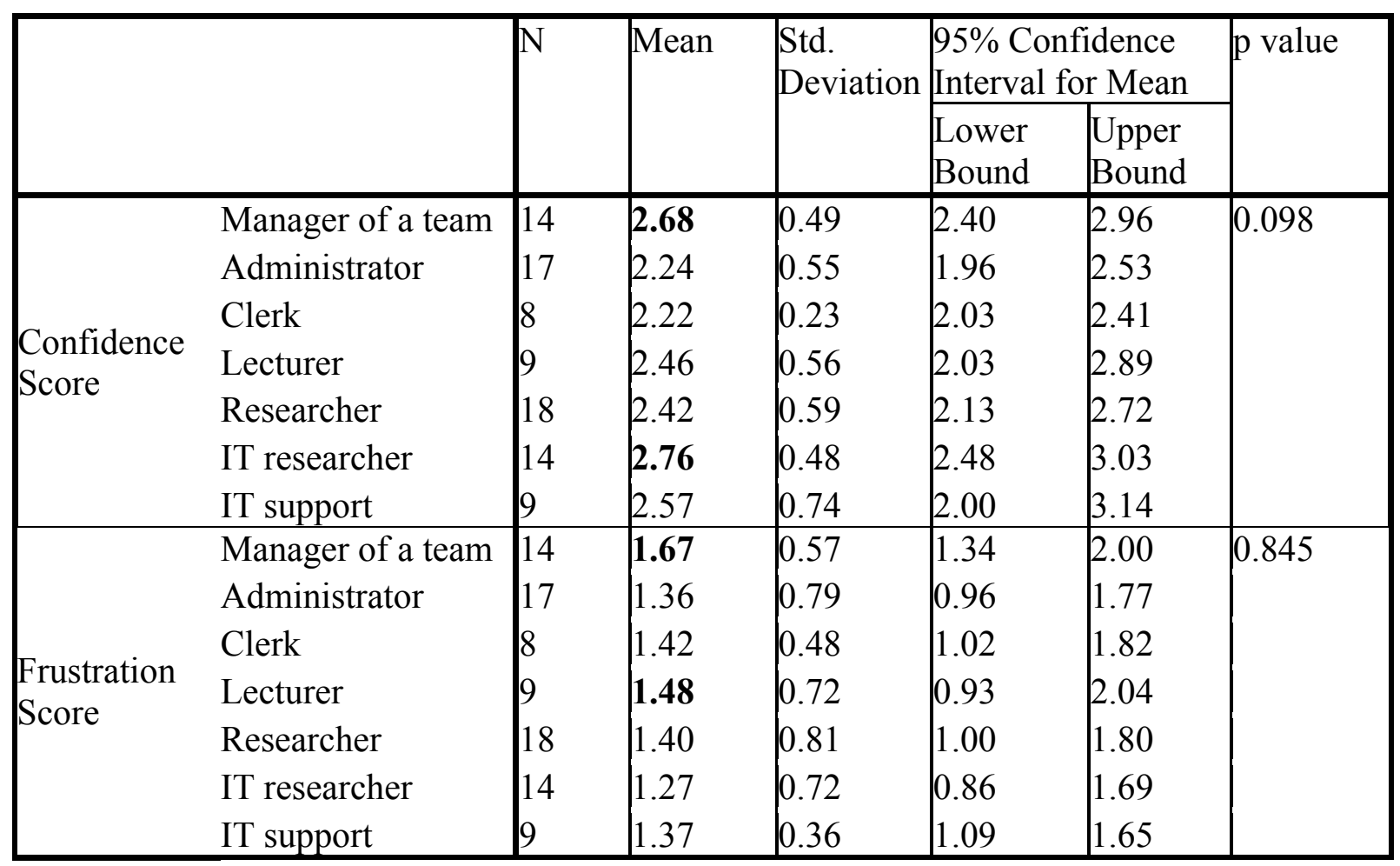

\subsection{Confidence Score and Frustration Score by Gender}

A one-way ANOVA test was carried out since the variables are normally distributed. Both women and men indicate confidence (mean over 2), and further demonstrate low levels of frustration (average score below 2). However, the results show a significant difference between men and women in the confidence score, where, on average, men were found to be more confident than women (see Table 4). This shows that there was a significant difference between men and women in rating confidence and frustration.

Table 4. Confidence and Frustration Score by gender. (*) Indicates a significant result

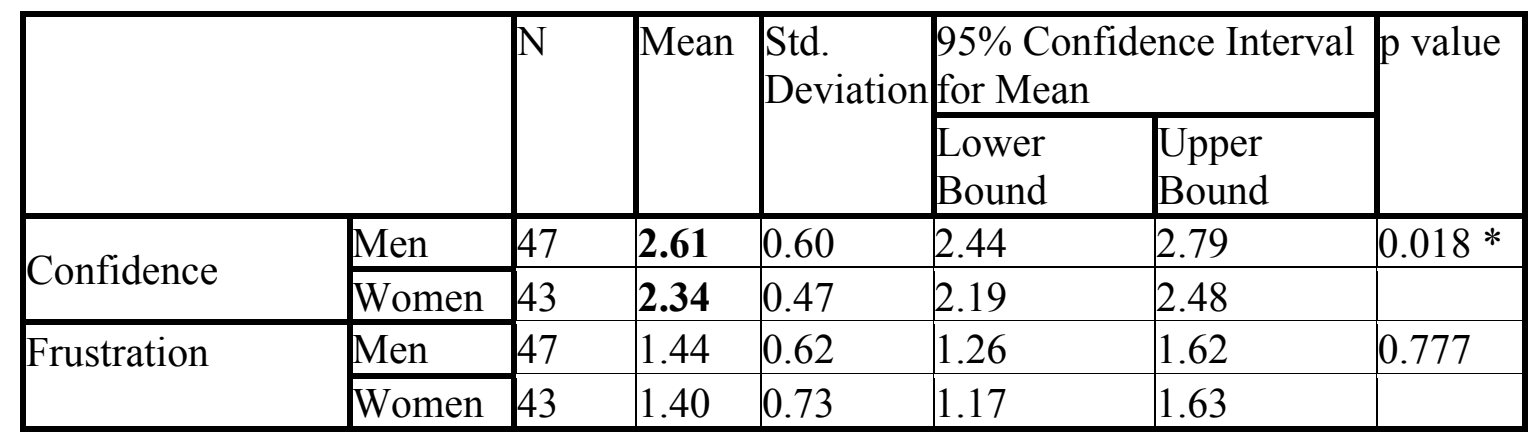


When examining the various items separately, we can see that women score below 2 whereas men score above 2 in relation to Question 3, with $\mathrm{p}=0.014$, indicating a significant difference between men and women where the latter do not feel confident in facing problems using SMDs (see Table 4). Also in Question 4, men were found to be more positive, stating they would stick to a problem until they could identify the solution. All the other questions followed the same trend: participants completing Task 2 were mostly men (9 of 12 participants). These results seem to indicate that confidence could have an influence on performance when participants are faced with a challenging task. However, there was no significant difference between the genders in terms of level of frustration.

\subsection{IT Support and its Relation to Success in Completing Task 1 and Task 2}

In order to analyse whether exposure to IT has a significant effect on their abilities, those participants who have been exposed to technology and whose job descriptions are somehow related to IT were placed within a category labelled 'IT-proficient', whereas those who use technology only as tool for completing their job role were classified as 'Others'.

A one-way Anova test was carried out, providing a $p$-value $=0.056$, which exceeds the $(p<0.05)$ level of indicating that there is no significant difference between 'IT-proficient' and 'Others'. It therefore it seems that exposure to IT did not reveal any difference in the ability to resolve a task.

When correlating the replies to the question 'How long do you have to wait before an IT support representative is available?' with the completion of the tasks performed, the study showed that if one has to wait for more than ten minutes for support to be provided there is a higher probability that the person would resolve the task on their own (see Table 5). 
Table 5 Comparing the time frame in which IT support was provided with the success rate in completing Tasks

Question: How long do you have to wait before an IT support representative is available?

\begin{tabular}{|l|l|l|l|l|}
\hline & Less than 10 minutes & \multicolumn{2}{|l|}{10 minutes or more } \\
\hline $\begin{array}{l}\text { Number of users that have completed } \\
\text { the task }\end{array}$ & Task 1 & Task 2 & Task 1 & Task2 \\
\hline IT-proficient users & 9 & 1 & 15 & 3 \\
\hline Other users & $37.5 \%$ & $25.0 \%$ & $62.5 \%$ & $75.0 \%$ \\
\hline Total & 18 & 3 & 40 & 7 \\
& $31.0 \%$ & $30.0 \%$ & $69.0 \%$ & $70.0 \%$ \\
\hline
\end{tabular}

The results show that if IT support provided in the workplace is not immediately available (more than 10 minutes to respond to a query), the participant demonstrated a greater ability to resolve Task 1. There was no significant difference between participants that were IT-proficient and those that were not. The trend for Task 2 was found to be similar, although the numbers were smaller. This shows that IT support response time influences the individual's problem-solving abilities in the context of short-term tasks.

\subsection{Recognising Icons and Respective Status: The SMD Visual Status Bar Task}

A score was assigned to the recognition task (see Figure 7), where an icon with a value of 1 was considered not difficult to recognise, a value of 2 was fairly difficult, and a value of 3 was quite difficult, with the latter requiring more in-depth knowledge of SMD usage. The maximum score one could achieve was 20, which was achieved by 5 participants (see Table 7). 


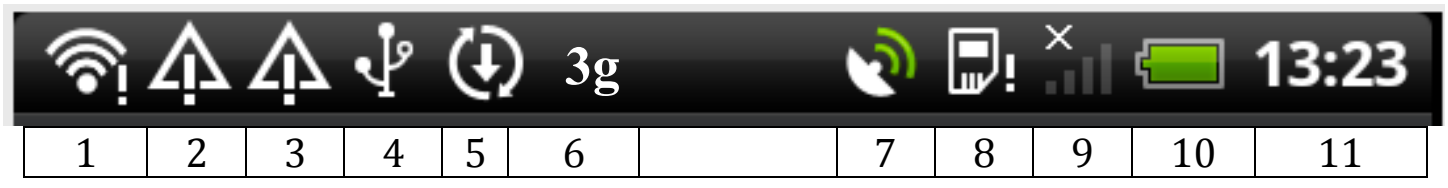

Figure 7 Match Icons with Description

Table 6 Visual Icon SMD status bar test: score related frequency percentage of success

\begin{tabular}{llll}
$\begin{array}{l}\text { Score } \\
\text { (Maximum }=\end{array}$ & $\begin{array}{l}\text { Number of participants } \\
\text { 20) }\end{array}$ & Percentage \% & Reference \\
$\mathbf{2 0}$ & 5 & 5.56 & \\
$\mathbf{1 9}$ & 1 & 1.11 & $\mathrm{~A}$ \\
$\mathbf{1 8}$ & 4 & 4.44 & \\
$\mathbf{1 7}$ & 25 & 27.78 & $\mathrm{~B}$ \\
\hline \hline $\mathbf{1 6}$ & 4 & 4.44 & \\
$\mathbf{1 5}$ & 13 & 14.44 & \\
$\mathbf{1 4}$ & 13 & 14.44 & \\
$\mathbf{1 3}$ & 7 & 7.78 & \\
$\mathbf{1 2}$ & 6 & 6.67 & \\
$\mathbf{1 1}$ & 7 & 7.78 & \\
\hline 9 & 2 & 2.22 & \\
7 & 2 & 2.22 & \\
0 & 1 & 1.11 & \\
\hline
\end{tabular}

Only 10 people (11.11\%) managed to score and identify enough icons to allow understanding of what action should be taken when interpreting the icon (see Ref A, Table 6). A total of $28 \%$ of the participants $(n=17)$ managed to identify commonly used icons such as time, battery, symbols indicating errors, and wireless connectivity (see Ref B, Table 6). The remaining participants $(\mathrm{n}=55$, $61 \%$ ) failed to recognise what most icons represented and identified only a select few (see Ref C, Table 6). The latter group of participants struggled to understand which errors were associated with wireless icons and what actions needed to be taken in order to solve particular errors.

Table 7 shows the percentage of participants that succeeded in the visual status bar test only for Task 1 , as well as the percentage of those managing to complete both tasks. 
Table 7. The relation of completed tasks and their ability to recognise items.

\begin{tabular}{|l|l|l|l|l|}
\hline \multicolumn{2}{|c|}{} & \multicolumn{2}{|l|}{ Ability to recognise items } & \multirow{2}{*}{\begin{tabular}{l} 
Total \\
\cline { 3 - 5 }
\end{tabular}} \\
\cline { 3 - 5 } & $\begin{array}{l}\text { At most of the tasks } \\
\text { was completed }\end{array}$ & $\begin{array}{l}\text { Both task were } \\
\text { completed }\end{array}$ & \\
\hline \multirow{2}{*}{ Low } & Count & 23 & 2 & 25 \\
& Percentage & $29.50 \%$ & $16.70 \%$ & $27.80 \%$ \\
\hline \multirow{2}{*}{ High } & Count & 55 & 10 & 65 \\
\cline { 2 - 5 } & Percentage & $70.50 \%$ & $83.30 \%$ & $72.20 \%$ \\
\hline \multirow{2}{*}{ Total } & Count & 78 & 12 & 90 \\
\cline { 2 - 5 } & Percentage & $100.00 \%$ & $100.00 \%$ & $100.00 \%$ \\
\hline
\end{tabular}

$\mathrm{X}^{2}(1)=0.852, \mathrm{p}=0.356$

The results in Table 7 above show that those participants who had a good understanding of the meaning of the icons on the mobile task bar and the message status, experienced high success in task completion. This was demonstrated by a change in the task bar icons, indicating the success or failure of an action. More specifically, participants struggled to understand which error was associated with a wireless icon (either the absence or presence of wireless connectivity) and what actions were needed in order to solve such problems.

\subsection{Attitude, Behaviour, and Obstacles in Completing the Tasks}

A video analysis was carried out in an attempt to investigate participants' attitudes and behaviours when performing the tasks as described in section 5.4. From the 90 participants involved in the study, videos of 62 participants were processed for the entire 15 minutes of recording; the remainder were discarded due to problems including the user moving out of camera view or reflection on the mobile monitor, which did not allow for a clear view of what was happening on the screen at all times. 
Each of the tasks in the experiment had various actions or stages that needed to be completed in order to solve the overall task. During the video analysis, all of the actions were assigned a value, referred to as atomic value, according to participant behaviour. The score was assigned on a 6-point scale (ranging from 0-5), where the behaviours of participants were categorised as follows: 1= does not understand what is happening and is completely lost; $2=$ is stuck/no action; $3=$ is stuck/repeats same action without trying a different approach; $4=$ took time (but completed it in the end); and $5=$ completed.

All participants completed some actions and, as such, successful actions participants choose to complete the task listed in figure 8 where not considered in the discussion below. For this study, other actions, which were referred to as 'Pain Points' (PPTs), were investigated as being more problematic. These have been considered in the users' behaviour analysis during problem-solving. An example of a PPT is when a problem is notified through an error message.

From the video analysis of Task 1 it was noted that 32 participants $(52 \%, n=62)$ did not know how to change a wi-fi connection. This was referred to as 'PPT1.1' and was related to the task 'Connect to wi-fi', entailing moving from one with no internet to one with an internet connection. This pain point did not generate an error message but the system status icon was key in aiding understanding of the problem.

Those participants who did not succeed in the first task were not able to perform the subsequent actions that depended on the completion of Task 1 (checking connectivity, configuring email, sending email). This was mostly due to the fact that the user could not correctly interpret the error message coming from the device. This caused most of them to repeat the same action a number of times without trying to understand how to go about solving the problem using the information available on the SMD.

For Task 2, 'Configure email account', there was PPT 2.2 (connect to internet by configuring wi-fi) and PPT 2.3 (send an email), with the pain point named 'PPT2.1' (see Figure 8).

Amongst the 62 participants, only 12 completed all PPTs and managed to send the email. 


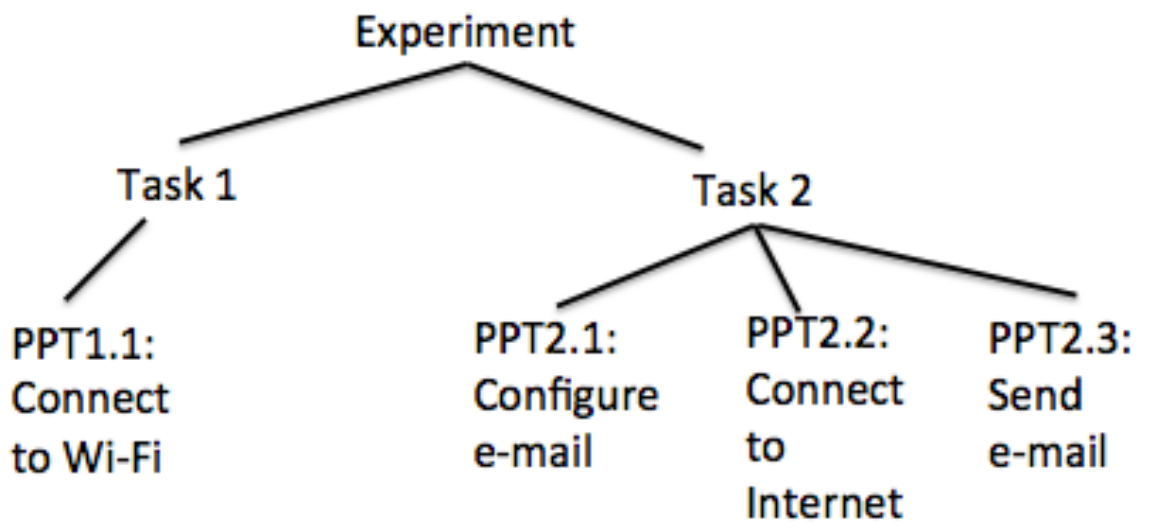

Figure 8: Experiment tasks and pain points

A one-tailed Pearson correlation test (see Table 8a) was used to analyse the PPTs in Task 2 because a positive relationship was expected between attitudes to complete tasks and the respective atomic value at PPTs. The one-tailed test provided a $p$-value $=0.035$, which did not exceed the $(p<0.05)$ level, indicating significance, showing a correlation between the attitude to complete a task with the atomic values assigned to the way in which participants completed the task.

Table 8a Pearson Correlation test

\begin{tabular}{|ll|l|}
\hline & & Atomic value \\
\hline Attitude to complete & Pearson Correlation & 0.231 \\
task & P-value (1-tailed) & 0.035 \\
& Sample Size & 62 \\
\hline
\end{tabular}




\begin{tabular}{|c|c|c|c|c|c|c|c|}
\hline \multirow[b]{2}{*}{ Profession } & & \multirow[b]{2}{*}{$\begin{array}{l}\text { Sample } \\
\text { Size }\end{array}$} & \multirow[b]{2}{*}{ Mean } & \multirow[b]{2}{*}{$\begin{array}{l}\text { Std. } \\
\text { Deviation }\end{array}$} & \multicolumn{2}{|c|}{$\begin{array}{l}95 \% \text { Confidence } \\
\text { Interval for Mean }\end{array}$} & \multirow[b]{2}{*}{$\mathrm{P}$-value } \\
\hline & & & & & $\begin{array}{l}\text { Lower } \\
\text { Bound }\end{array}$ & $\begin{array}{l}\text { Upper } \\
\text { Bound }\end{array}$ & \\
\hline \multirow{7}{*}{$\begin{array}{l}\text { Attitude to } \\
\text { complete task }\end{array}$} & IT Researcher & 15 & 3.47 & 1.552 & 2.61 & 4.33 & 0.328 \\
\hline & Researcher & 11 & 2.91 & 1.921 & 1.62 & 4.20 & \\
\hline & IT Support & 6 & 2.17 & 1.722 & 0.36 & 3.97 & \\
\hline & Clerk & 6 & 2.00 & 2.757 & 0.00 & 4.89 & \\
\hline & Administrator & 8 & 2.38 & 2.066 & 0.65 & 4.10 & \\
\hline & Lecturer & 8 & 2.38 & 2.066 & 0.65 & 4.10 & \\
\hline & Manager of a team & 8 & 1.50 & 1.604 & 0.16 & 2.84 & \\
\hline \multirow[t]{7}{*}{ Atomic value } & IT Researcher & 15 & 3.33 & 1.291 & 2.62 & 4.05 & 0.477 \\
\hline & Researcher & 11 & 3.09 & 1.446 & 2.12 & 4.06 & \\
\hline & IT Support & 6 & 2.67 & 1.862 & 0.71 & 4.62 & \\
\hline & Clerk & 6 & 3.17 & 1.329 & 1.77 & 4.56 & \\
\hline & Administrator & 8 & 2.88 & 1.246 & 1.83 & 3.92 & \\
\hline & Lecturer & 8 & 3.75 & 1.389 & 2.59 & 4.91 & \\
\hline & Manager of a team & 8 & 2.25 & 1.581 & 0.93 & 3.57 & \\
\hline
\end{tabular}

All 62 participants attempted to configure the given email account: 39 of them $(63 \%, n=62)$ first tried to connect using Wi-Fi, and 32 of these 39 participants $(52 \%, n=62)$ attempted to send an email. Both actions were required to complete Task 2. Table $8 \mathrm{~b}$ shows, for example, how PPT2.1 (configure email) was tackled when participants, according to their job role, attempted to complete the task. Again, users were often not able to read through the messages presented by the SMDs when they encountered a problem with the configuration.

Moreover, it was observed that those who conduct research as part of their job role tend to attain a higher performance score across all stages. Results show that different users tackle problems differently when facing difficulties using technology, and also that their approach can be attributed to their day-to-day job: for example, their role at the place of work influenced users that managed to complete the task by identifying the problem. This group of participants, who did not previously know how to solve the particular problem but were able to follow a logical sequence, succeeded in solving the task. On the other hand, users with a managerial role found it more difficult to solve problems when facing difficulties. 


\subsection{Session Analysis - Focus on Actions, User Actions, and their Respective Pain Points}

The results detailed in this section stem from Task 2. The focus was centred on gaining insight into how participants deal with the issues they experience, especially when they have the capacity to adhere to a logical number of steps to carry out a task. Attention was directed to those results seen to be demonstrating pain points established throughout the session analysis captured on video. Table 9 details a list of pain points that were identified at a particular time during the session analysis. As described above, for this study a pain point may be defined as an event that causes the subject to stop working towards achieving their goal for one of the reasons detailed. This could affect the subject in various ways. A list of various pain points and corresponding attitudes were identified, suggesting the difficulties experienced by the participants in carrying out various events. The pain points included: (1) something that caused the user to change the sequence of actions he or she was following; (2) the time taken to complete an action due to lack of understanding or familiarity with the task; (3) being completely stuck and not knowing what to do; and (4) being presented with an error message as a result of which the user knows what is wrong but it is too complex to allow the user to identify the next action. Each of the pain points appears to be aligned with one or more stages, and the mean time (in seconds) allocated was recorded. The findings emphasise that few subjects were able to complete sequences when obstacles were experienced. This means that those participants who identified problems in the first sequence did not progress to the next stage in the task. More specifically, the majority of the sample stopped trying to complete the task. Those who continued to follow the sequence ignored the error message and made subsequent attempts to complete the task. 
Table 9: Pain Point with corresponding attitude and mean time towards tackling them (Dependent Variable: Time in seconds)

\begin{tabular}{|c|c|c|c|c|}
\hline Pain Point Identified & Description of observed action & $\begin{array}{l}\text { Mean } \\
\text { Time }\end{array}$ & $\begin{array}{c}\text { Std. } \\
\text { Deviation }\end{array}$ & $\mathrm{N}$ \\
\hline \multirow{4}{*}{ Configuring Email } & $\begin{array}{l}\text { Does not understand what is happening; } \\
\text { completely lost }\end{array}$ & 299.00 & 215.179 & 16 \\
\hline & $\begin{array}{l}\text { Stuck/repeats same action without trying a } \\
\text { different approach }\end{array}$ & 297.77 & 159.819 & 22 \\
\hline & Took time (but completed it in the end) & 306.50 & 122.709 & 10 \\
\hline & Completed & 131.00 & 50.192 & 6 \\
\hline \multirow{4}{*}{ Sending Email } & $\begin{array}{l}\text { Does not understand what is happening; } \\
\text { completely lost }\end{array}$ & 172.86 & 126.518 & 7 \\
\hline & $\begin{array}{l}\text { Stuck/repeats same action without trying a } \\
\text { different approach }\end{array}$ & 189.41 & 116.858 & 17 \\
\hline & Took time (but completed it in the end) & 216.00 & 104.644 & 6 \\
\hline & Completed & 105.50 & 28.991 & 2 \\
\hline \multirow{5}{*}{ Checking Connectivity } & $\begin{array}{l}\text { Does not understand what is happening; } \\
\text { completely lost }\end{array}$ & 222.50 & 153.442 & 2 \\
\hline & Stuck/no action & 89.50 & 101.116 & 2 \\
\hline & $\begin{array}{l}\text { Stuck/repeats same action without trying a } \\
\text { different approach }\end{array}$ & 148.22 & 110.911 & 9 \\
\hline & Took time (but completed it in the end) & 214.25 & 86.063 & 4 \\
\hline & Completed & 28.20 & 25.607 & 5 \\
\hline Choosing another Wi-Fi & Completed & 56.67 & 45.829 & 3 \\
\hline $\begin{array}{l}\text { Figuring out how device } \\
\text { works }\end{array}$ & Took time (but completed it in the end) & 81.67 & 34.078 & 3 \\
\hline
\end{tabular}

\subsection{Logging Mean Time when Configuring an Email Account on Different Platforms}

For this study, an average time to complete tasks per sequence could be established to measure the skills of the participants. Time to complete a sequence did not vary much between the different SMDs used for this study. All timings to complete sequence were noted for each SMD when extracting the results. Analysis was carried out in line with the SMD being used by participants.

Three different sequences are detailed in Figure 9 with the respective SMD supporting three different platforms (Windows Mobile, Android and IOS) utilised in order to complete the second task. Figure 9 details the results that show that users identified a significant difficulty when configuring the mail app using the Windows platform. Moreover, as shown in the subsequent graph, a greater portion of time was dedicated to the task when using the Windows platform, followed by IOS when configuring a mail client using the default app available on the respective SMD. 
Figure 9: Mean time taken when configuring an email comparing three different approaches (Results are categorised according to mobile platform used)
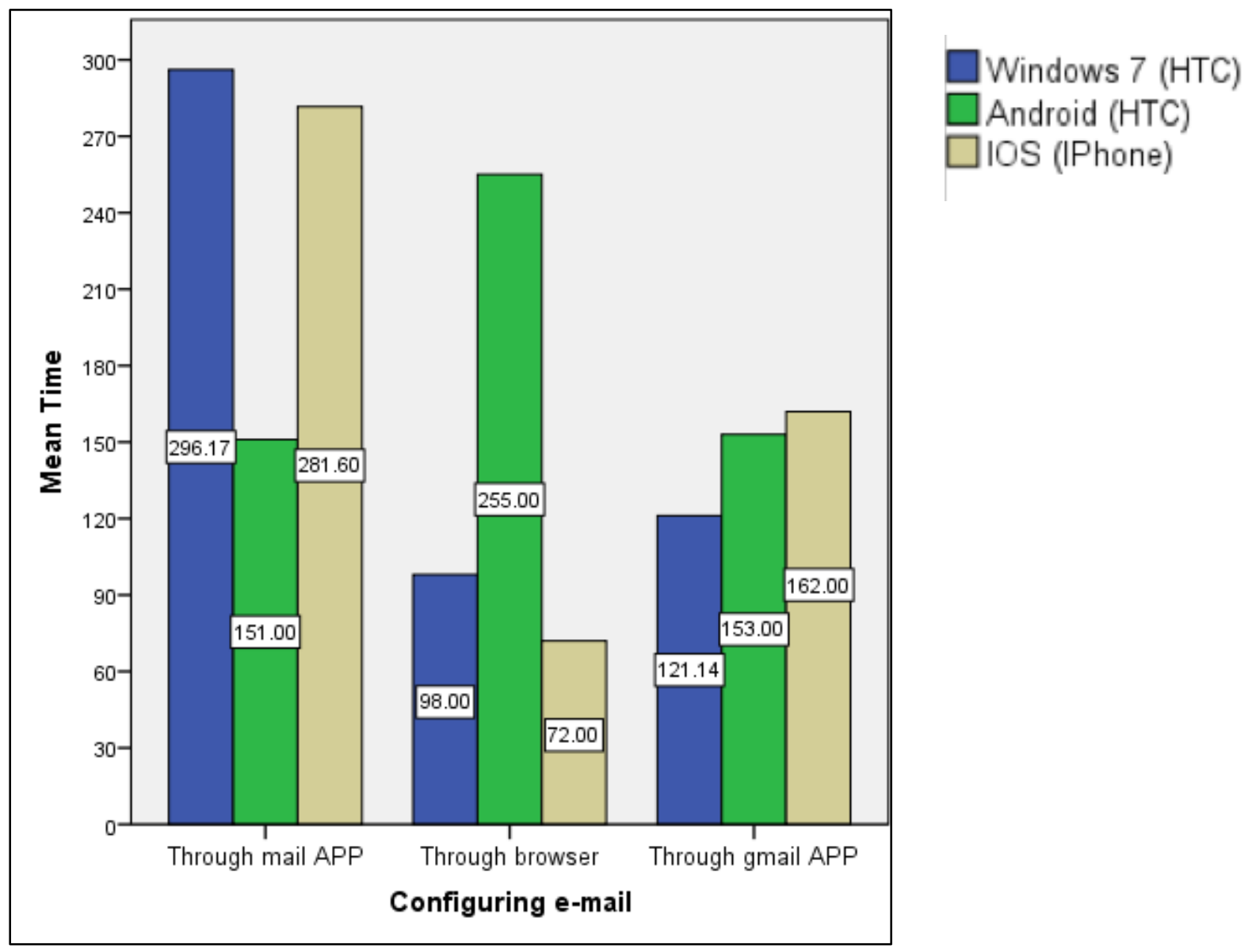
$\square$ Android (HTC) $\square$ IOS (IPhone)

During the video analysis of the study, it was observed that most users either failed to understand or failed to read through the message being presented when they encountered a problem with an app or with the configuration of a setting. When logging the pain point at which participants experienced difficulties, it was seen that the most challenging aspect was encountered when users were required to move their focus away from the sequence of events they were tackling to another sequence of actions. The video analysis showed that the main problems participants faced were in relation to internet connectivity due to a lack of understanding of the error messages generated and, therefore, a low score was achieved when calculating the atomic value during that particular pain point. 


\section{$7 \quad$ Summary and Discussion}

The use of SMDs is increasing in the work setting; however, a number of obstacles are limiting complete uptake. Although SMD designers are always seeking to improve applications and operating systems in an effort to better support users in self-managing their mobile devices, problems still occur when a user is faced with an unfamiliar smart mobile platform, regardless of task familiarity. The high task-failure rate in this study seems to indicate that despite a familiarity with tasks, users are not necessarily acquiring transferable skills when using SMDs.

This study appears to indicate that, irrespective of what role and position a person may adopt in their place of work, and regardless of one's ability to solve tasks, everyone experiences difficulties when challenged with unfamiliar settings and when coming across a system that does not act as users expect. If error messages are provided they are not always sufficiently understood and, therefore, are not always helpful. If no error message is displayed only some people — who seem to be researchers - are able to think outside the box and identify different approaches. People's attitudes towards a task are correlated with their ability to find a solution.

Problem-solving skills have an impact on the time utilised to complete a task and confidence in oneself appears to influence performance. When comparing success rates with confidence levels, the study has shown that confident users have higher success. Moreover, the findings show that the users participating in the study did not feel frustrated — despite the time limit and failing to solve the given tasks. One reason for this could be that there was no personal reason for carrying out the tasks.

Self-reported confidence seems to be gender-biased, where males have shown higher confidence ratings but not higher-problem solving results. The effectiveness of IT-support in the place of work seems to influence users' ability to solve tasks independently. This, in turn, influences users' confidence and how they may choose to tackle a problem. It also seems that users' actions and confidence rates are connected with the type of job they do which, in turn, influences their perception of technology and their self-directed problem-solving ability.

Those individuals who conduct research as part of their job role tend to obtain higher performance scores across all stages and there is also a correlation between attitude when completing a task and the atomic values assigned to how participants complete tasks.

Error messages are not always valuable to support users when recovering from challenges. Furthermore, the role of the key aspects of memorability requires more in-depth examination in an 
effort to determine whether or not users acknowledge they have experienced a particular system state before, and whether they remember the steps needed in order to overcome the problem at hand.

\section{Conclusions}

The objective of the present study was to observe how people solve familiar tasks on unfamiliar mobiles and to determine the manner in which they tackle the challenges they encounter, their confidence and attitude, their frustration and success rate.

The findings show that, despite the great effort that designers have invested in developing apps and operating systems that are easy and intuitive to use, users seems unable to transfer what they have learnt on one platform to another platform, and to guide their actions. From the results of the study we can offer various recommendations for software designers and employers considering the adoption of smart mobile devices in the workplace:

1. In the workplace, users might be more effective if allowed to use their own device or one with which they are familiar. This has been debated in Olalere et al. (2015). In this case, users might be better positioned to tackle the problem with a better attitude.

2. Self-reported technology-confident users are not exempt from experiencing problems. Technological changes, such as the use of an unfamiliar smart mobile device, seem to increase the chance of encountering problems.

3. Adopting new technology in the workplace requires a learning period with support provided during this period.

Although a few modes of support can be found on popular smart phones, there continues to be a need for research to understand how SMD users can best engage with new devices and features, and how support systems can be designed in such a way as to foster self-directed approaches. These might include the provision of personalised support or collaborative support solutions that cater to different people with different skills, backgrounds, and needs. This might also allow technology to be more accessible and to increase productivity, as well as users' confidence, thus facilitating a positive attitude and experience when learning in the workplace. 


\section{References}

Ashton, D. N. (2004). The impact of organisational structure and practices on learning in the workplace. International Journal of Training and Development, 8(1), 43-53. http://doi.org/10.1111/j.1360-3736.2004.00195.x

Cairns, P., \& Cox, A. L. (2008). Research methods for human-computer interaction (Vol. 12). Cambridge University Press New York, NY, USA.

Dix, A. (2007). Why examples are hard, and what to do about it. In Intefaces 72 (ne, pp. 16-18). Retrieved from http://alandix.com/academic/papers/examples-2007/alansinterfaces2007.pdf

Field, A. (2009). Discovering Statistics Using SPSS. SAGE Publication, London.

Giannakouris, K., \& Smihily, M. (2012). One in two enterprises provides staff with portable devices for mobile Internet connection ICT usage in enterprises 2012 - Statistics in Focus 46/2012. Eurostat, (46/2012).

Harrison, R., Flood, D., \& Duce, D. (2013). Usability of mobile applications: literature review and rationale for a new usability model. Journal of Interaction Science, 1(1), 1-16. http://doi.org/10.1186/2194-0827-1-1

Hiemstra, R. (1994). Self-directed learning. The Sourcebook for Self-Directed Learning, in: T.Husen \& T.N. Postlethwatte (eds) Pergamon Press, Oxford pp. 9-20.

Jambon, F., Golanski, C., \& Pommier, P. J. (4-9 Nov. 2007). Meta-evaluation of a context-aware mobile device usability. Proceedings - International Conference on Mobile Ubiquitous Computing, Systems, Services and Technologies, UBICOMM 2007, International Conference on, Papeete, 2007, pp.21-26. IEEE http://doi.org/10.1109/UBICOMM.2007.8

Kleanthous Loizou, S., \& Dimitrova, V. (2012). Adaptive notifications to support knowledge sharing in close-knit virtual communities. User Modeling and User-Adapted Interaction. http://doi.org/10.1007/s11257-012-9127-y

Kravcik, M., \& Klamma, R. (4-6 July 2012). Supporting Self-Regulation by Personal Learning Environments. IEEE 12th International Conference on Advanced Learning Technologies, Rome, 2012 pp. 710-711. IEEE http://doi.org/10.1109/ICALT.2012.192

Latham, G., \& Locke, E. (2002). Building a practically useful theory of goal setting and task motivation. American Psychologist. Retrieved from $\mathrm{http}: / /$ scholar.google.com/scholar?hl=en\&btnG=Search\&q=intitle:Building+a+Practically+Usef $\mathrm{ul}+$ Theory + of + Goal + Setting + and + Task + Motivation\#1

Lazar, J., Jones, A., \& Shneiderman, B. (2006). Workplace user frustration with computers: an exploratory investigation of the causes and severity. Behaviour \& Information Technology, 25(3), 239-251. http://doi.org/10.1080/01449290500196963

Lunenburg, F. C. (2011). Goal-Setting Theory of Motivation. International Journal Of Management, Business, And Administration, 15(1), 1-6.

McAuliffe, Marisha B. and Hargreaves, Douglas J. and Winter, Abigail J. and Chadwick, Gary (2008). Does pedagogy still rule? In: 19th Annual Conference of Australasian Association for Engineer Education, 7-10 December 2008, Central Queensland University, Yeppoon. 
McGuffin, M Balakrisha, R. (2005). "Fitts" law and expanding targets: Experimental studies and designs for user interfaces. ACM Transactions on Computer-Human Interaction, 4(12), 388422.

Mourão, S., \& Okada, K. (2010) "Mobile Phone as a Tool for Data Collection in Field Research," World Academy of Science, Engineering and Technology, Vol. 70, 2010, pp. 222-226.

Nielsen, J. (1994). Usability engineering. Morgan Kaufmann Publishers Inc.

Nielsen, J., \& Landauer, T. K. (1993). A mathematical model of the finding of usability problems. In CHI 1993 (pp. 206-13). New York: ACM Press.

Olalere, M., Abdullah, M. T., Mahmod, R., \& Abdullah, a. (2015). A Review of Bring Your Own Device on Security Issues. SAGE Open, 5(2). http://doi.org/10.1177/2158244015580372

Pintrich, P. R., Conley, A. M., \& Kempler, T. M. (2003). Current issues in achievement goal theory and research. International Journal of Educational Research, 39(4-5), 319-337. http://doi.org/10.1016/j.ijer.2004.06.002

Rogers, Y., Connelly, K., Hazlewood, W., \& Tedesco, L. (2010). Enhancing learning: a study of how mobile devices can facilitate sensemaking. Personal Ubiquitous Computing. 14, 2 (February 2010), 111-124. DOI=http://dx.doi.org/10.1007/s00779-009-0250-7

Schmidt, A., \& Braun, S. (2006). Context-aware workplace learning support: Concept, experiences, and remaining challenges. In W. Nejdl, \& K. Tochtermann (Eds.), Innovative Approaches for Learning and Knowledge Sharing (pp. 518-524). Lecture Notes in Computer Science. Berlin/Heidelberg: Springer, http://dx.doi.org/10.1007/11876663_46 